\title{
Solution Design of Research for Emergency Management
}

\author{
Xia Peng ${ }^{1, a}$, Rui $\mathrm{Li}^{2, \mathrm{~b}}$ \\ ${ }^{1}$ College of Information Science and Technology, Bohai University, Jinzhou, 121013, China \\ ${ }^{2}$ College of Foreign Languages, Bohai University, Jinzhou, 121013, China \\ aaxialiu58@sohu.com, bselinalr@163.com
}

Keywords: emergency management research; solution; design; overall framework; basic ideas

\begin{abstract}
Research solution of emergency management is also in its infancy, for these situations, theoretical results is not perfect, practice mainly rely on subjective decision-making, the efficiency of emergency management is low, emergency response are ineffective, this paper is the research solution of emergency management. The scheme mainly includes the value of the theory and practice, the research content and the overall framework, basic ideas and research methods, main features and innovative points in these four aspects. The aims of this study are to provide a complete research solution of emergency management, then point out the concrete research ideas and research methods, thereby it will enhance the emergency management theoretical level and practice ability.
\end{abstract}

\section{Introduction}

"The people's Republic of China law to deal with unexpected events" define the unexpected events that it is suddenly, cause or may cause serious harm to society, need to take emergency measures to respond to natural disasters, accidents, public health incidents and social security incidents. The affection of urban emergency management is related to the social stability, economic development and people's life, but also the assessment of government management ability is one of the standards. This research schemes use the method of system analysis, game theory and behavior management theory and methods, to city emergency government emergency management mechanism, Study on the main line and main content " City emergencies evolvement mechanism and management structure, city emergency government emergency management decision model, city emergency management mechanism, government emergency management decision analysis" To solve the city emergency government emergency management mechanism in theory and method. Based on the analysis of the present situation of Chinese and foreign management experience, study of city emergency conditions the government emergency management mechanism, will be helpful for the government in the event of an emergency condition to make timely, accurate, scientific decision-making, efforts will be unexpected events caused by the adverse consequences of reduced to a minimum, improve the effectiveness of contingency management. The aims of this study were to study the city emergency government emergency management to provide a complete programmer of research, and pointed out the concrete research ideas and plan, so as to improve the government emergency management theoretical level and practice ability.

\section{Theories and Practice Value}

China, which has the most number of population and city on the world, not only has great significance on city disaster related theory and practice of research and development, but also has an important significance of other developing countries.

\section{The Theoretical Value}

The promoting of urban emergency management research can enrich and supplement the city public security management theory and method system of knowledge.

China's urban public management under the joint efforts of scholars in and outside the province has made great achievements, which urban safety management and urban disaster management has 
been a rapid development and application, but the urban emergency management theory, method and system far from perfect, affect the further development of the urban public management theory. This study combines the features of the urban emergency management, decision theory, game theory and behavior theory based on the city emergency management mechanism and the emergency law, to provide a new theoretical perspective for the city Emergency Management, to promote the progress of the urban public management theory and methods.

A long time, for the management of urban disaster events, has always stressed that "prevention" approach to management, but in practice people attach importance to pre-control at the same time, but there is ignored after the control of the phenomenon. The same time, the theory of urban disaster event, emergency management, the method is very imperfect, the urban emergency management is basically blank. In this study, the characteristics and mechanism for the unexpected events of the urban, proposed the framework of the emergency management system, building in urban emergency decision-making model to study the behavioral and psychological groups affected by the incident conditions, to enrich and supplement in a particular environment (city), emergency management theory and methods of great significance.

\section{The Practical Value}

Create a system of urban emergencies under the conditions of the emergency management system and programs to provide a theoretical basis, improve the ability of the Chinese government on the urban emergency management.

This paper deeply study the characteristics of the incident and internal evolution of emergency management models, and the seek to effectively respond to emergencies, this paper come up with effective ways and means in order to reduce urban emergencies arising from destruction and restore normalcy as soon as possible. Provide a theoretical basis for improving urban management department of emergency management behavior. Help solve the event of an emergency existing in reality, improper handling leading to greater damage emergency management issues.

With the development of modern cities, this giant system of the urban become increasingly complex, the emergency and its impact becomes more hair miscellaneous. The sudden outbreak has the following characteristics, uncertainty, loss severity is difficult to predict, the possibility of disastrous consequences. Therefore, the mechanism of the occurrence, development and evolution of the city emergency needs in-depth research, real-time measurement and monitoring of events development and to establish a system of emergency management methods and a comprehensive emergency management system, and from more than one level to establish an efficient operation of urban emergency management mechanism, to provide the necessary theoretical and methodological support for the government to implement effective emergency management. Therefore, enhancing the urban emergency management capability has great significance for urban construction and development.

\section{Content and The Overall Framework}

\section{Research Content}

On the basis of analyzing domestic and international emergency management study of the recent literature, combined with the characteristics of urban emergencies around the core theories and methods of government behavior in the conditions of city emergencies. For the following research study:

(1) Mechanism and management structure of urban emergencies evolution. From the occurrence of unexpected events, development, evolution and diffusion mechanism of the evolution, the four aspects of urban emergencies, emergency management, design urban multi-level framework for all levels, analyze emergency coordination process and the implementation process.

(2) Government emergency management decision-making model for urban emergencies Analyze the main body of the emergency management, the government emergency decision-making goals, guidelines and typical decision-making behavior two aspects of the emergency decision-making behavior; Give the city emergency classification principle, construction of government emergency management system is put forward; emergent event classification K-Modes model of cluster 
analysis and classification of the emergency of the dynamic fuzzy model and algorithm based on uncertain; the affected population aversive behaviors of government emergency decision model.

(3) Management mechanism of urban emergency. Design contingency incentive and punishment mechanism. Design the operating mechanism of the Government Emergency Management, from the five aspects of organizational behavior, legal governance, execution behavior, supervision and management and protection of behavior proposed to strengthen and improve and propose measures of the Government's emergency management decision-making in the conditions of urban emergencies.

(4) Management decision-making case of government emergency. Specific cities, for example, deeply analyze the government emergency management activities, emergency management decision-making method of application, a culture of prevention and rescue team-building, the construction of the emergency management system built from the government emergency management organization system, and pointed out the problems and make recommendations accordingly.

\section{The Overall Framework}

The overall project framework shown in Fig. 1.

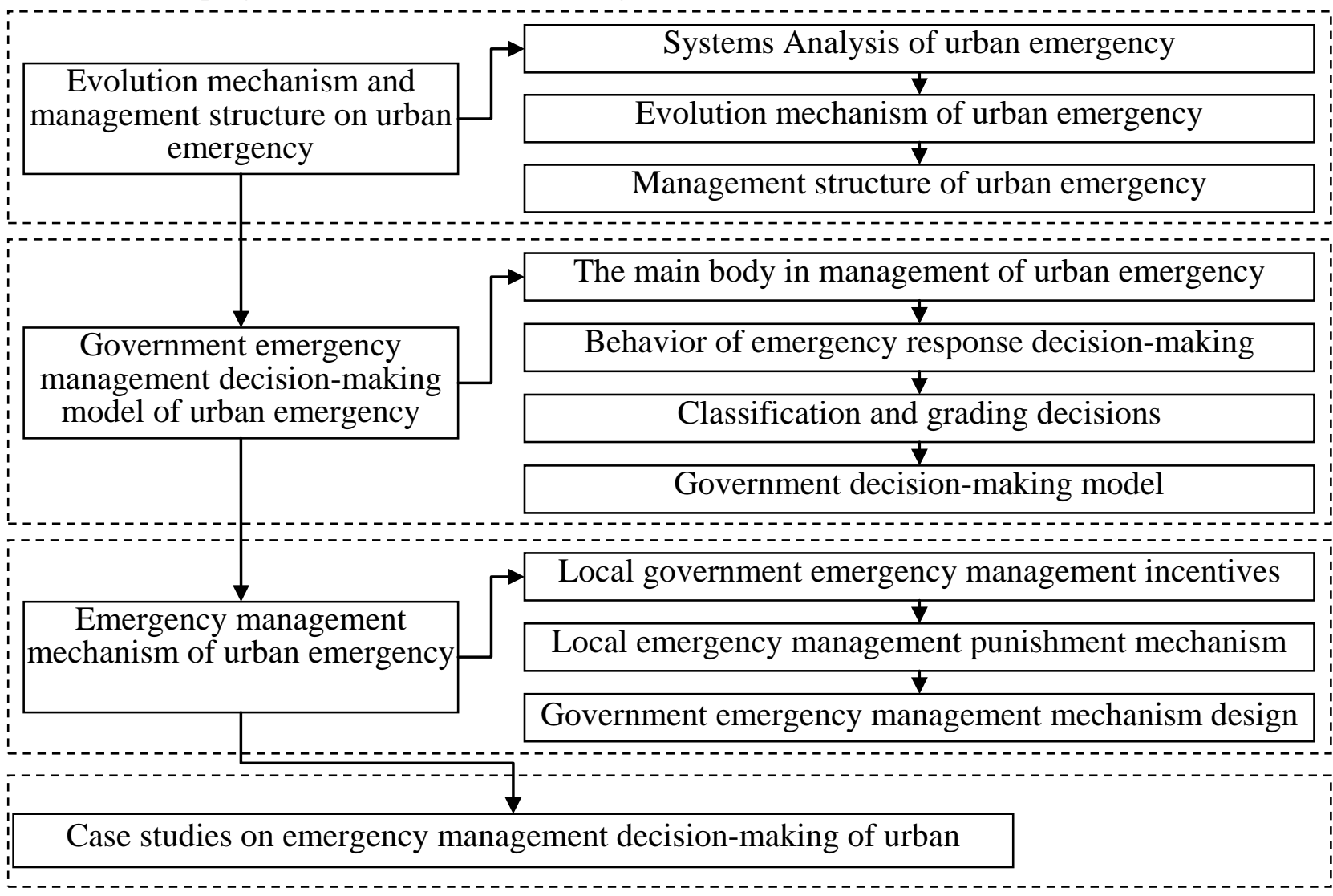

Fig.1. The overall framework of research scheme of government on urban emergency management operational mechanism

\section{Basic Ideas and Research Methods}

The basic train of thought and research methods are as follows:

(1) This paper proposes the theme, identify research objectives and the main research contents by means of literature retrieval, analysis of domestic and foreign emergency management development trends, combined with the actual needs of city management,

(2) analyze of three aspects of city emergency evolution mechanism by using the method of system analysis, from the occurrence of unexpected events, development and diffusion. On this basis, design the multi level framework of city emergency management. 
(3) put forward the emergency classification K-Modes cluster analysis method by using fuzzy decision making model and non additive probability model, build the population uncertainty aversion behavior non additive government emergency decision model, and gives the corresponding decision process.

(4) design a city hall emergency management incentive and punishment mechanism from the game theory analysis of the static game method and stochastic game theory analysis method; Draw lessons from the mechanism design theory, the organization behavior, legal management, execution behavior, supervision and security act in five aspects of design of government emergency management mechanism.

(5) Use the method of case analysis, with specific city as an example, analysis of city emergency management present situation, problem, and draw lessons from the research results of this paper gives some decision methods, mechanism design and relevant suggestions.

(6) Take active part in relevant domestic and international academic conference, strengthen academic and government emergency management departments cooperation and contact, improve the scientific research and application value.

\section{Main Features and Innovations}

The main characteristic and innovation are as follows:

(1) Establish city emergency classification K-Modes clustering model and emergency grading fuzzy dynamic model, and give the corresponding algorithm. Through the analysis of emergency management body and government emergency decision objectives, standards, followed in the city emergency classification principles and construction based on the system, the emergent event classification K-Modes model of cluster analysis and classification of the emergency of the dynamic fuzzy model, can scientifically assisted the government in the emergency management of unexpected classification of events to make scientific judgment and decision making.

(2) Set up government emergency decision model for a population with uncertain aversive behaviour non additive belief. Based on the emergency condition of human behavior analysis, construction of the affected population with uncertain aversive behaviour non additive beliefs of government emergency decision model can help the government in emergency management emergency management effectively in the affected population.

(3) Design incentive, punishment and operation mechanism of city emergency management. Government Emergency incentive and punishment mechanism using game theory analysis, an analysis designed to provide a theoretical basis for the government's emergency management operation mechanism; government emergency management operational mechanism should include organizational behaviour, legal governance, execution behaviour, supervision and behaviour of management and security five areas.

(4) Analyse the evolution mechanism of emergencies, the design includes prevention, emergency preparedness, emergency response and recovery process four components of the city emergency management framework. The urban emergencies include the mechanism of evolution from the occurrence of unexpected events, development and diffusion in three stages; the framework of the city emergency management including prevention, emergency preparedness, emergency response and recovery and of handling four part contingency framework for the implementation of the coordination of various departments of the multi-level process.

\section{Conclusion}

The aim of emergency management functions of the government is to reduce the risk of vulnerability and improve the ability to respond to disasters. Traditional contingency management problems are mainly: link of forecast is fairly weak, there are difficulties among the many departments, coordination command means should be enhanced, and emergency rehabilitation assessment is not full. Urban emergency management research in China has attracted more and more attention, for a particular city case analysis to guide other city emergency management has 
important sense. The Shuangqing Forum, which is held in December 2006 by the National Natural Science Foundation Committee Policy Board and the Department of Management Sciences, thinks that the city emergencies emergency management from the perspective of multidisciplinary research. Literature research and data indicate that urban disaster emergency management issues is a very complex in all aspects of the social, natural systems, involving people, things, management organization, patterns, facilities, technology, legal regulations, while Fortunately, considering the public health social conditions, and psychological reactions. To see the evolution from the decision-making body and the disaster itself, there is incomplete, from the Institute need to look at the theoretical method for urban disaster emergency management research, involving psychology, behavioral science, management science, economics, mathematics, and many disciplines. In short, for China, the urban emergencies is still quite a lot of topics worthy of further study. Recently, the number of China's urban disaster emergency management also began to receive the academic attention, but emphasis on the interpretation of the analysis model assumes that the majority of emphasis on case studies compared with foreign, empirical research in China is relatively small. Use results of research theories and methods to obtain targeted for the emergency management case studies of particular cities, the city can not only help improve the emergency management efficiency and effectiveness, and the other cities also have important reference value.

\section{References}

[1] X.S. Han, "Decision-making Models and Operational Mechanisms of Government on Urban Emergency Management," Doctor's Degree of Harbin Institute of Technology, 2009.

[2] K. Zhang, M. Li, J.F. Qiang, "Emergency IDSS for Hubei Province," Computer Development \& Applications, vol. 20, no. 4, pp. 17-21, 2007.

[3] Behnam Malakooti, "Systematic decision process for intelligent decision making," Journal of Intelligent Manufacturing, vol. 121, no. 5, pp. 1342-1355, 2009.

[4] Hawaf Abdalhakim, Mohamed Abdelfattah, "A Visualization-based Intelligent Decision Support System Conceptual Model," Springer Netherlands, 2011.

[5] SHAO Lin, LIN Boliang, "Environment Impact Assessment of Desert Railway Based on Fuzzy Comprehensive Evaluation," Journal of the China Railway Society, vol. 31, no. 5, pp. 84-89, 2009.

[6] Yang XG, Yang ZH, Cao SY, "Key techniques for the emergency disposal of Quake lakes," Natural Hazards, vol. 52, no. 1, pp. 43-56, 2010.

[7] Berry, J., Hart, W.E.,et al., "Sensor Placement in municipal water networks with temporal integer programming models," Journal of Water Resource Planning and Management, vol. 132, no. 4, pp. 218-224, 2006.

[8] BERRYJ W, FL EISCHERL ,HART W E, et al., "Sensor placement in municipal water networks," Journal of Water Resources Planning and Management, vol. 131, no. 3, pp. 237-243, 2005.

[9] Jorge Pinto, Humberto Varum, Isabel Bentes et al., "A Theory of Vulnerability of Water Pipe Network," Water Resources Management, vol. 75, no. 1, pp. 96-105, 2010.

[10] Z. X. Gao, J. Y. Zhang, L. Y. Cui, "Based on the CBR and RBR mixed reasoning intelligent diagnosis technology of rolling mill gear box," Journal of Beijing University of Technology, vol. 37, no. 9, pp. 474-477, 2010.

[11] Tomáš Ludík and Jaroslav Ráček, "Process Methodology for Emergency Management," IFIP Advances in Information and Communication Technology, vol. 35, no. 9, pp. 302-309, 2011. 